\title{
Review \\ Development and Prospect of UAV-Based Aerial Electrostatic Spray Technology in China
}

\author{
Yali Zhang ${ }^{1,2}$, Xinrong Huang ${ }^{1,2}$, Yubin Lan ${ }^{2,3}$, Linlin Wang ${ }^{2,3}$, Xiaoyang Lu ${ }^{1,2}$, Kangting Yan ${ }^{1,2}$, \\ Jizhong Deng ${ }^{1,2, *}$ and Wen Zeng ${ }^{1,2, *}$ \\ 1 College of Engineering, South China Agricultural University, Wushan Road, Guangzhou 510642, China; \\ ylzhang@scau.edu.cn (Y.Z.); xrhuang@stu.scau.edu.cn (X.H.); luxiaoyang@stu.scau.edu.cn (X.L.); \\ ktyan@stu.scau.edu.cn (K.Y.) \\ 2 National Center for International Collaboration Research on Precision Agricultural Aviation Pesticide \\ Spraying Technology, Wushan Road, Guangzhou 510642, China; ylan@scau.edu.cn (Y.L.); \\ wlinlin@stu.scau.edu.cn (L.W.) \\ 3 College of Electronic Engineering and College of Artificial Intelligence, South China Agricultural University, \\ Wushan Road, Guangzhou 510642, China \\ * Correspondence: jz-deng@scau.edu.cn (J.D.); zengwen@scau.edu.cn (W.Z.)
}

check for updates

Citation: Zhang, Y.; Huang, X.; Lan, Y.; Wang, L.; Lu, X.; Yan, K.; Deng, J.; Zeng, W. Development and Prospect of UAV-Based Aerial Electrostatic Spray Technology in China. Appl. Sci. 2021, 11, 4071. https://doi.org/ 10.3390/app11094071

Academic Editor: Sylvain Bertrand

Received: 12 April 2021

Accepted: 28 April 2021

Published: 29 April 2021

Publisher's Note: MDPI stays neutral with regard to jurisdictional claims in published maps and institutional affiliations.

Copyright: (c) 2021 by the authors. Licensee MDPI, Basel, Switzerland. This article is an open access article distributed under the terms and conditions of the Creative Commons Attribution (CC BY) license (https:/ / creativecommons.org/licenses/by/ $4.0 /)$.

\begin{abstract}
Aerial electrostatic spray technology for agriculture is the integration of precision agricultural aviation and electrostatic spray technology. It is one of the research topics that have been paid close attention to by scholars in the field of agricultural aviation. This study summarizes the development of airborne electrostatic spray technology for agricultural use in China, including the early research and exploration of Chinese institutions and researchers in the aspects of nozzle structure design optimization and theoretical simulation. The research progress of UAV-based aerial electrostatic spray technology for agricultural use in China was expounded from the aspects of nozzle modification, technical feasibility study, influencing mechanism of various factors, and field efficiency tests. According to the current development of agricultural UAVs and the characteristics of the farmland environment in China, the UAV-based aerial electrostatic spray technology, which carries the airborne electrostatic spray system on the plant protection UAVs, has a wide potential in the future. At present, the application of UAV-based aerial electrostatic spray technology has yet to be further improved due to several factors, such as the optimization of the test technology for charged droplets, the impact of UAV rotor wind field, comparison study on charging modes, and the lack of technical accumulation in the research of aerial electrostatic spray technology. With the continuous improvement of the research system of agricultural aviation electrostatic spray technology, UAV-based electrostatic spray technology will give play to the advantages in increasing the droplets deposition on the target and reducing environmental pollution from the application of pesticides. This study is capable of providing a reference for the development of the UAV-based agricultural electrostatic spray technology and the spray equipment.
\end{abstract}

Keywords: agricultural aviation; UAV; plant protection; review; electrostatic spray technology; droplet deposition; aerial pesticides application; charge to mess ratio

\section{Introduction}

Electrostatic spray technology for agricultural aviation is the application of traditional electrostatic spray technology in an airborne platform. It is one of the research topics that scholars in the field of agricultural aviation always pay attention to. Agricultural aerial electrostatic spray technology is mainly based on induction, corona, and contact charging methods to charge the droplets. Under the action of high voltage static electricity, charged droplets make rapid directional deposition along the electric field line in the air and settle on the target [1,2]. For this reason, aerial electrostatic spray can effectively reduce drift loss during aerial pesticide application, improve droplet deposition, and mitigate 
environmental pollution [3,4]. Carlton et al. [5] from the Agricultural Research Service of the United States Department of Agriculture (USDA-ARS) designed an electric rotating electrostatic nozzle in 1966, which was the first scientific research institution in the world to carry out research on aerial electrostatic spray technology for agriculture. Carlton also obtained the invention patent of the aerial electrostatic spray technology in 1999 [6]. The patent was certified by the United States Department of Agriculture as the world's first and only commercially proven airborne electrostatic spray system for agriculture [7]. SES (Spectrum Stack Sprayers, Inc., Houston, TX, USA) has been awarded an exclusive license to manufacture and market this innovative technology. Subsequently, scientific research institutions in the United States, Brazil, Canada, Switzerland, and China have conducted a large number of studies to gradually improve the research and application of electrostatic spray in agricultural aviation [8-10].

The research of electrostatic spray technology for agricultural aviation started relatively late in China but developed rapidly. Especially in recent years, the rapid development of plant protection UAVs in China has attracted scholars to make a lot of attempts on the research and application of UAV-based electrostatic spray technology. This study introduced the early exploration of aerial electrostatic spray technology in China from the aspects of nozzle structure design optimization, theoretical simulation, and field experiment with manned aircraft platforms. Then, the research progress of UAV-based electrostatic spray technology in China was emphatically expounded upon, and the existing problems were discussed as well. It is proposed that future research should be carried out in the measurement technology for charged droplets, the influence of UAV rotor wind field on charged droplets, comparative study of various charging methods, and other aspects, so as to increase the accumulation of research on aerial electrostatic spray technology based on an agricultural UAV platform. This study can provide a reference for the development of the agricultural aviation electrostatic spray technology and the spray equipment.

\section{Early Exploration of Aerial Electrostatic Spray Technology in China}

In the 1970s, China began to study the new technology of electrostatic spraying for agricultural application [11]. In 1977, Shenyang Spray Factory used hand-held sprayers to carry out field spraying experiments on the seedlings and young trees of cloves and found that the application of electrostatic spraying treatment could increase the amount of pesticides applied per unit area of plants while reducing the labor intensity [12]. After the application of electrostatic spray technology in hand-held and knapsack sprayers, it has also achieved success in the application of ground agricultural machinery equipment in greenhouses, orchards, and other operating scenarios [13,14]. A large number of studies on the effects of electrostatic spray equipment have been carried out on droplet size, droplet deposition distribution in each part of crop canopy, nozzle structure, and working parameters on droplet quality, etc. [15-19].

In 2005, China introduced the electrical parts and nozzles of the aerial electrostatic spray system from the SES company and carried out simulation tests and flight tests [20], marking the beginning of China's research in the field of aerial electrostatic spraying. Two years later, universities and scientific research institutions in China began to comprehensively study the aerial electrostatic spray technology based on manned aircraft platforms in aspects of hardware structure improvement, mechanism of influencing factors, and theoretical simulation.

\subsection{Hardware Structure Improvement}

Hardware structure improvement research refers to the adjustment or structural modification of system parameters such as electrode material, nozzle size, rotor number, and nozzle position of aerial electrostatic spray systems [21].

In 2007, Ru et al. [22] introduced a structured design on a double-nozzle for an aerial electrostatic sprayer and theoretically analyzed the space field induced by the double-nozzle and the impact on the size and charging droplets from the space field. 
Zhou et al. [23] improved the design of an aerial electrostatic single-nozzle from the aspects of an electrostatic electrode, nozzle material, nozzle processing technology, connection mode of high voltage wire and electrode, rotating screw joints, overflow valve body, and so on, in order to meet the requirements for application and large-scale production.

In terms of the electrode of electrostatic nozzles, Ru et al. [24] modified the original cylindrical electrode to a cone-shaped electrode according to the features of aerial electrostatic spraying. The effect of charging voltage on the charge to mass ratio and deposition distribution of the new aerial electrostatic system was tested under simulated flight conditions. It was found that the electrostatic spray was beneficial to increase the average deposition of charged droplets on the lateral, bottom, and back sides of the neutral target significantly. Jin et al. [25] improved the ring electrode of an aerial electrostatic nozzle and conducted an experimental study on the droplet size and the charging effect of droplets after the improvement. Results showed that droplet size was influenced by nozzle diameter, spraying pressure, and charging voltage, of which the spray pressure indicated the strongest effect, and charging voltage showed the weakest effect. The charge to mass ratio increased with the increase in voltage, reaching a maximum of $2.09 \mathrm{mC} / \mathrm{kg}$, and tends to saturation at $8 \mathrm{kV}$. The charge to mass ratio decreased with the increase in droplet size, but the change was not rapid.

\subsection{Research on Mechanism of Influencing Factors}

The settling process of charged droplets is restricted by environmental factors, controllable factors, and target parameters during spraying operation, thus affecting the operation quality of the electrostatic spraying system. Among these influencing factors, environmental factors include temperature, humidity, wind speed, soil, etc.; controllable parameters include charging voltage, spraying flow, spraying pressure, flight altitude, flight speed, etc.; target parameters include crop objects, target morphology, leaf inclination, and insect pest types and habits, and so on [21].

Yang et al. [26] studied the influence of different crosswinds wind speed conditions and electrostatic voltage on charging characteristics through indoor simulation of natural wind and constant wind environment, providing a basis for strengthening the anti-drift ability of charged spray droplets in the settling process. Chen et al. [27] analyzed the characteristics of the electrostatic field induced by the ring electrode with the help of Fluent software (Version 6.3). It was found that the higher charging voltage or smaller electrode spacing (when the distance between the induction electrode ring and the nozzle was less than $10 \mathrm{~mm}$ ) could effectively improve the charge effect and spray quality.

\section{Rapid Progress of UAV-Based Electrostatic Spray Technology}

\subsection{Research Background}

In 2014, China's agricultural pesticide application was still dominated by large fixedwing aircraft, supplemented by rotary-wing UAVs [28]. However, since 2015, with the urbanization process in China, the rural labor force population has become less and less. Meanwhile, with the improvement of living standards, automatic pesticide application tools have gradually been accepted by farmers [29]. Nowadays, plant protection UAVs have maintained a booming trend in the field of agricultural plant protection. China has taken an internationally leading position in terms of technology, quantity, and product types of agricultural plant protection UAVs [30].

Figure 1 shows the increasing number of plant protection UAVs and operating areas covered in China from 2014 to 2020. The number of plant protection UAVs has reached 106,000 units with an operation area covered of 64 million $\mathrm{hm}^{2}$ in 2020. In this context, Chinese scholars began to put forward the idea of applying aerial electrostatic spray technology to UAVs, while there are few reports on this topic worldwide. 


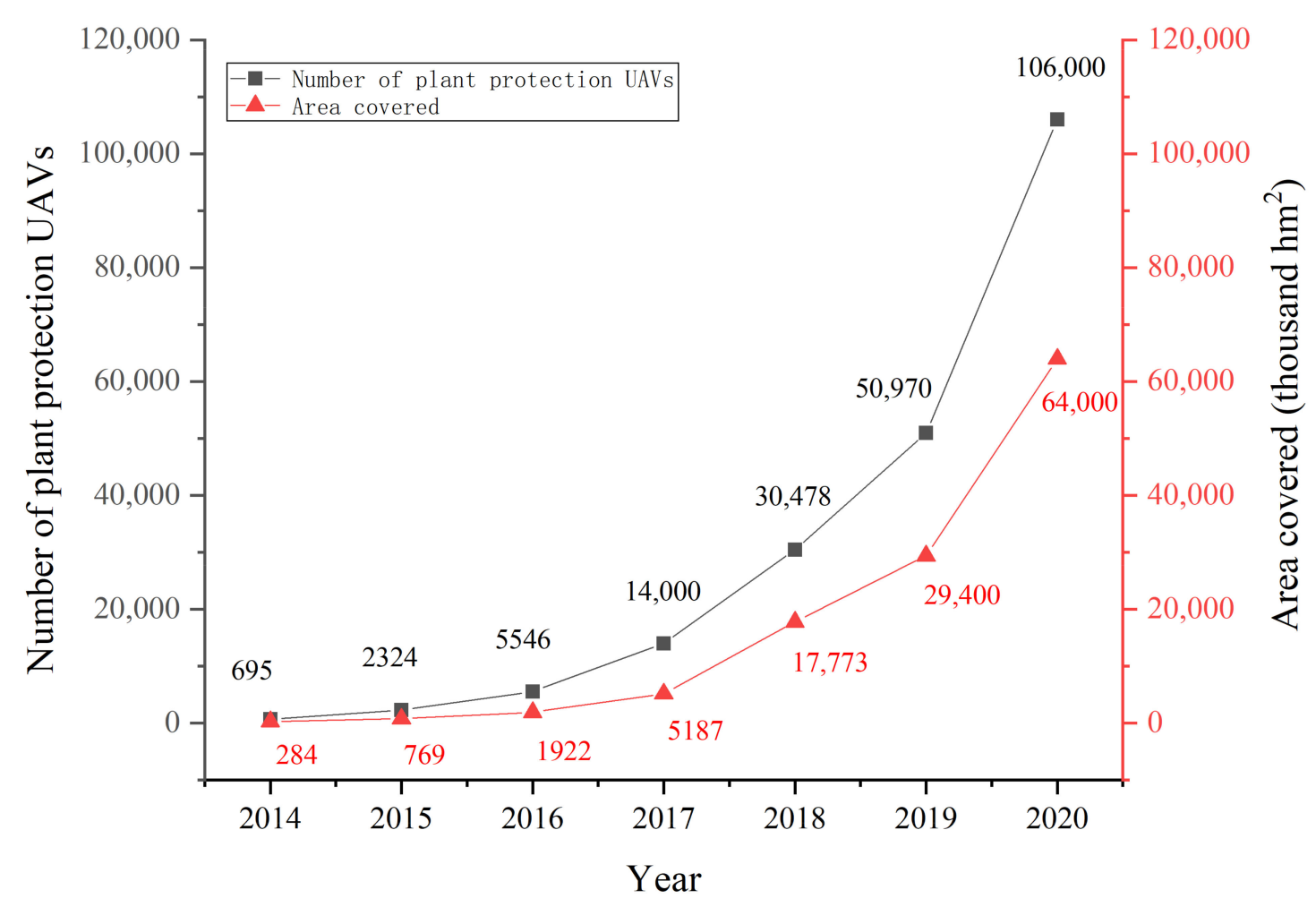

Figure 1. Increasing number of plant protection UAVs and operating area covered in China (2014-2020).

\subsection{Beginning of the Research on UAV-Based Electrostatic Spray Technology}

In 2015, Ru et al. [31] tried the first combination of electrostatic spray technology and plant protection UAV with an XY8D unmanned helicopter and carried out field tests in a rice field, as shown in Figure 2. A preliminary experiment on spray pressure, flow rate, and charging voltage were conducted to determine the optimal parameters for field tests. Field spraying test results showed that the droplet deposition and coverage rate on the target crop was effectively improved by the UAV-based electrostatic spraying when compared with non-electrostatic spraying. The influence of environmental factors and physical properties of the liquid was not verified in this experiment. However, the first study of carrying the electrostatic spray system on a UAV was of great value. Chinese scholars then began to make continuous innovations and breakthroughs in UAV-based electrostatic spray technology.

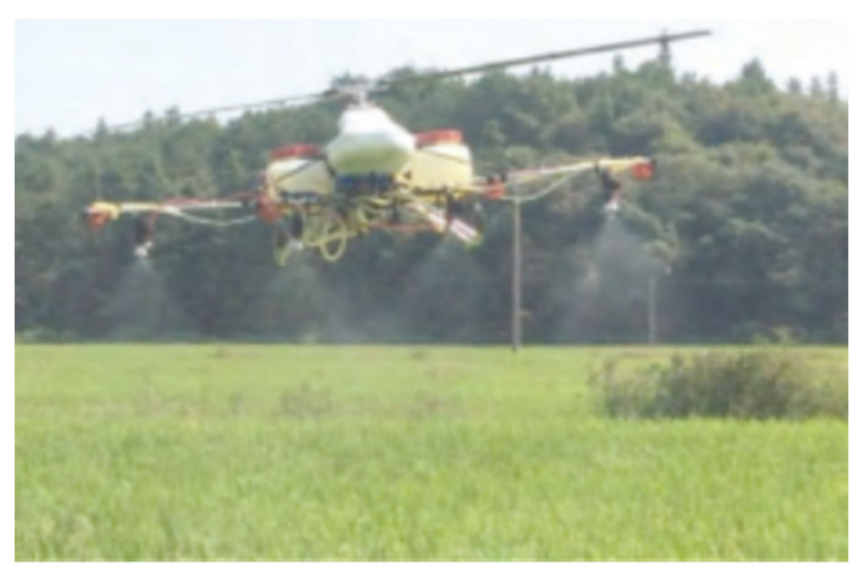

Figure 2. Rice field test with an XY8D UAV-based electrostatic spray system [31]. 


\subsection{Continuous Optimization of UAV-Based Electrostatic Spray Technology}

Chinese researchers have carried out a series of optimization work from the aspects of nozzle modification, test effect comparison, and mechanism of influencing factors in order to meet the precise operation requirements of UAV-based electrostatic spray system in practical application and to improve the droplet deposition on the target crops.

In terms of nozzles modification, Wang et al. [32] improved the conventional nozzles for multi-rotor plant protection UAVs. An inductive type electrostatic centrifugal nozzle was developed by combining agricultural electrostatic spray technology with a centrifugal atomizing nozzle. Besides, the spraying flow stability test and droplet deposition effect of the system were studied. When the charging voltage of the nozzle reaches $8 \mathrm{kV}$, the charge to mass ratio reaches the maximum value of $0.59 \mathrm{mC} / \mathrm{kg}$.

In terms of comparison with the test results of non-electrostatic spray, Jin et al. [33] from Nanjing Forestry University designed an electrostatic spray system for the AF118 helicopter. Through the effective spraying width and droplets deposition characteristics, it is found that the effective spraying width of electrostatic spray was smaller than that of non-electrostatic spray. The total droplet deposition number of electrostatic spray (9-36 drops $\left./ \mathrm{cm}^{2}\right)$ was higher than that of non-electrostatic spray (6-26 drops $/ \mathrm{cm}^{2}$ ). Lian [34] used YG-6 six-rotor UAV to carry an electrostatic spray system. Through an indoor performance test, the optimal operating parameter combination of the system was determined (spraying height is $50 \mathrm{~cm}$, charging voltage is $9 \mathrm{kV}$, spraying pressure was $0.3 \mathrm{MPa}$ ). This parameter combination was used to test the electrostatic spray effect of outdoor UAVs. The result showed that the average deposition density of droplets sprayed above the target by electrostatic spray was $16.1 \mathrm{more} / \mathrm{cm}^{2}, 13.6 \%$ higher than that by non-electrostatic spray. The average sediment density in the middle was $28 \mathrm{more} / \mathrm{cm}^{2}$, which increased by $32.6 \%$. Cai [35] developed an aerial electrostatic spray system based on an F-50 plant protection UAV. The spray system adopts contact charge, and the experimental research is carried out according to the factors of the rotor wind field, such as wind speed, charge to mass ratio, flight height, and flight speed. Through field spraying experiments, as shown in Figure 3, it was found that the flight height is an important factor affecting the deposition amount and the horizontal deposition uniformity but has little effect on the vertical deposition uniformity. Zhao et al. [36] proposed a method of charging the liquid in two isolated water tanks with positive and negative charges respectively by a high-voltage electrostatic generator based on the contact charge mode to solve the problem of insufficient adsorption rate of droplets on the target back when using an aerial electrostatic spray. Aerial electrostatic spraying test stand and UAV electrostatic spray system were designed, which proved that it was feasible to develop a charge transfer loop in space to improve the adsorption performance of droplets. An electrostatic physical model of aerial electrostatic spray based on charge transfer space loop is shown in Figure 4. Zhang et al. [37] developed a fan-shaped induction electrostatic spray system based on a six-rotor UAV and defined the corresponding operating parameters (spray height $50 \mathrm{~cm}$, spray pressure $0.3 \mathrm{MPa}$, and charging voltage $9 \mathrm{kV}$ ). Compared with non-electrostatic spray, the electrostatic spray had more concentrated droplet deposition and smaller drift. The average droplet deposition density at the top of the electrostatic spray sampling device was 16.1 drops $/ \mathrm{cm}^{2}$ higher than that of non-electrostatic spray, and the deposition density in the middle was $28 \mathrm{drops} / \mathrm{cm}^{2}$ higher than that of non-electrostatic spray. Therefore, aerial electrostatic spray could significantly improve droplet deposition and prevent drift. 


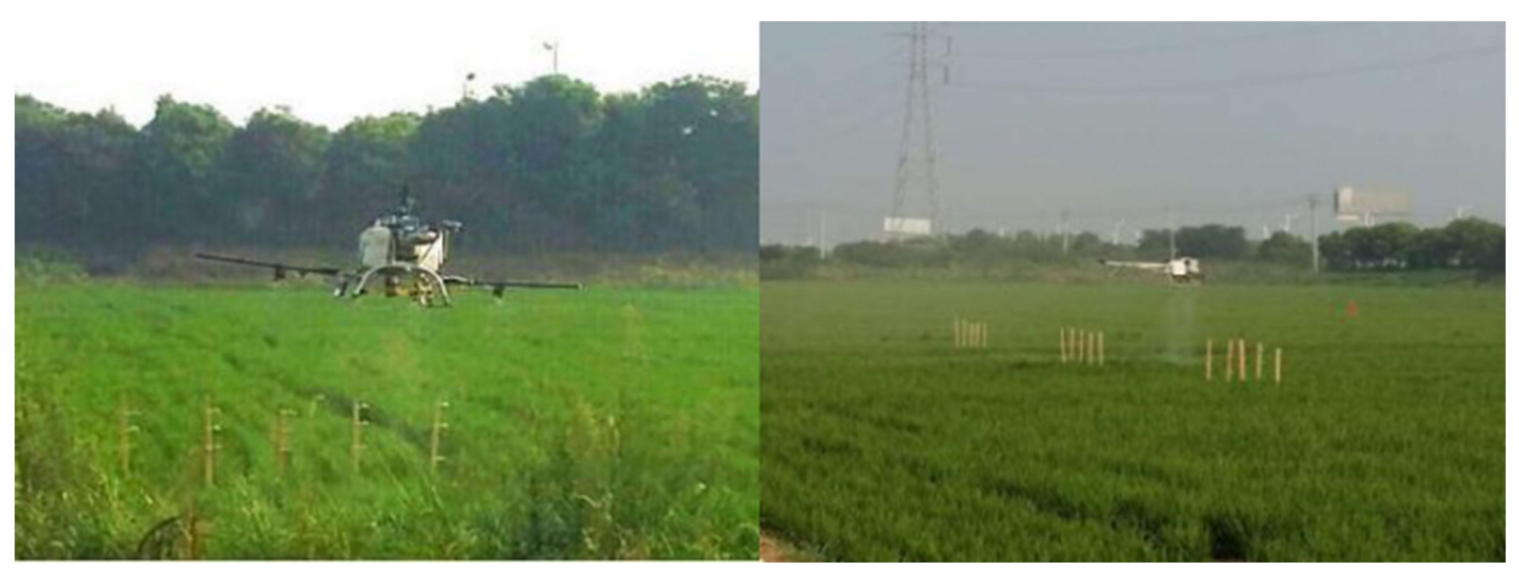

Figure 3. UAV paddy field spraying operations [35].

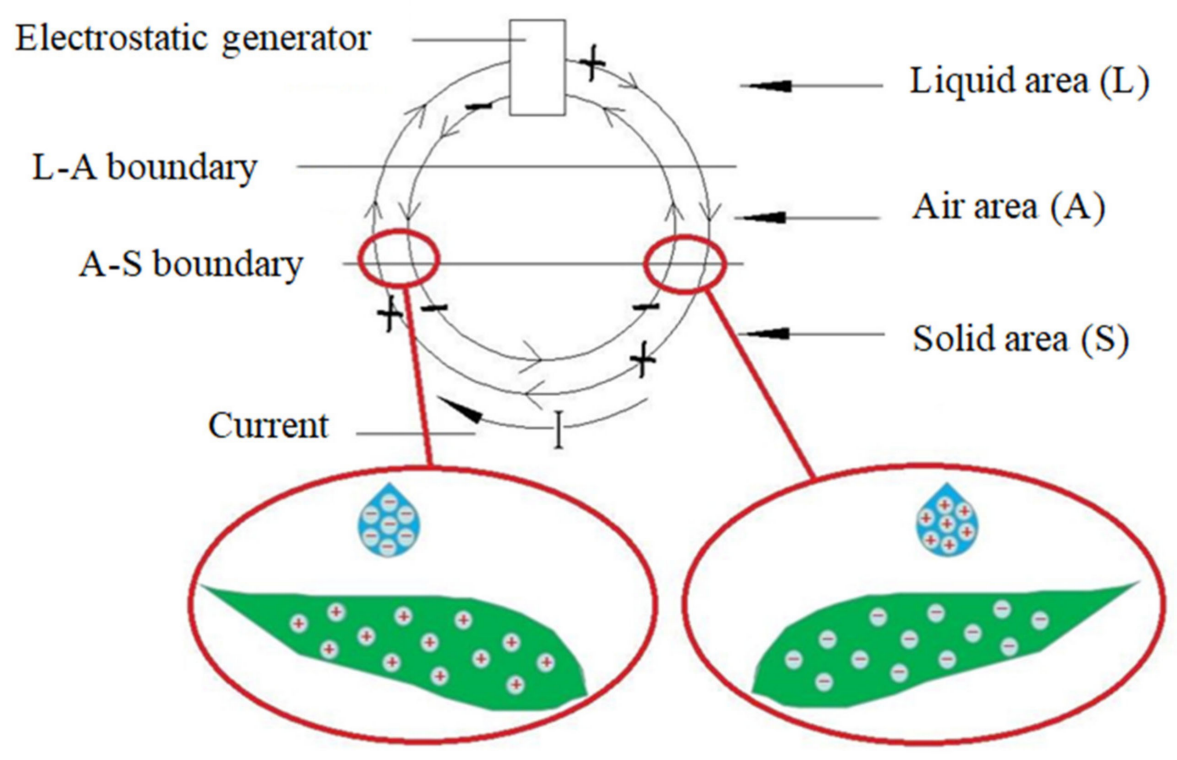

Figure 4. Electrostatics physical model of aerial electrostatic spraying based on charge transfer space loop [36].

In terms of the mechanism of influencing factors, $\mathrm{Bu}$ [38] designed an electrostatic spray system based on the FR-200 large-load unmanned helicopter with a maximum load of $80 \mathrm{~kg}$. The charge and spray characteristics of the electrostatic spray system were studied, and the prediction models of the charge to mass ratio and droplet size were established. The characteristics of deposition and drift of electrostatic spray of heavy load unmanned helicopter were analyzed by field experiments. It was concluded that the charge voltage, flight height, and crosswind wind speed were the main factors affecting the drift and deposition of an electrostatic spray of FR-200. The results showed that the charge voltage had the greatest influence, followed by the crosswind wind speed, and the flight height had the least influence. Based on the research results, the mathematical model was established between the center distance of droplet mass and droplet drift rate and the charged voltage, flight height, and crosswind wind speed. Wu et al. [39] introduced response surface analysis (RSM) into the optimization design of spray parameters of Electrostatic spray system of UAVs. A response surface model with injection pressure and nozzle diameter as design variables and droplet charge to mass ratio as optimization objectives was constructed. The performance tests of the new electrostatic spray system under different nozzle diameters, spray pressures, and electrostatic voltages were carried out. It showed that the nozzle met the theoretical requirements of optimal biological particle 
size and the requirements of hydraulic spray control for most crop diseases and insect pests. The validity of the model was also proved. In addition, multivariate analysis of variance showed that nozzle diameter, spray pressure, and electrostatic voltage have important effects on performance. The influence of the two factors on the deposition density and uniformity is the spray pressure, the nozzle diameter, and the optimal combination of the factor levels to obtain the best results. Chinese scholars also carried out research on multiple operating parameters and their interaction effects on the performance of aerial electrostatic spray systems. Lu et al. [40] simulated the spray performance of UAV-based electrostatic spray systems at different flight heights by measuring the droplet diameter under different nozzle apertures and system pressures and obtained the optimal flight parameter combination. Zhao et al. [41] studied the spray deposition with three factors: spraying duration, charging voltage, and flight height. The experimental results showed that the back-front ratio of droplets on the back and front of leaf targets could reach $158.8 \%$ under indoor conditions, and the droplet size on the back was smaller than that on the front. The number of droplets increased with the accumulation of spraying time without affecting the back-front ratio. Higher charging voltage and lower spraying height for the aerial electrostatic spray system can achieve a better deposition effect and higher back-front ratio. Wang et al. [42] established theoretical equations of droplet group charge based on the water inductive charging theory and then studied the effects of electrode figuration (electrode ring diameter, electrode spacing, spray pressure, and charge voltage) on droplet charging and spray performance through experiments. Under the action of an electrostatic field, the droplet size decreased obviously with the increase in charged voltage. The charge performance improved with the decrease in electrode ring diameter. Lan et al. [43] studied the impact of electrode materials on the deposition characteristics of an aerial electrostatic system with different orifice sizes, system pressures, and charging voltages. The results showed that red copper was the best electrode material. Li et al. [44] simulated five factors, such as temperature, humidity, electrode ring diameter, electrostatic voltage, and nozzle flow, using a BP model based on Neuroshell software and studied the effects on the charge to mass ratio of airborne electrostatic droplets. The final linear regression model indicated that the charging voltage and flow rate were the two main influencing factors on the droplet charge to mass ratio.

\subsection{Spray Efficiency Experiments of UAV-Based Electrostatic Spray Technology}

Wang et al. [45] designed a bipolar contact oil-powered single rotor aerial electrostatic spray system for plant protection UAVs. The static electricity system was used to spray the static electricity oil agent and the conventional water-based chemical agent. Besides, the spray droplet deposition distribution and the control effect of wheat aphid and rust were tested. The result showed that the deposition per unit area was $0.0486 \mu \mathrm{g} / \mathrm{cm}^{2}$, the standard deviation of deposition amounts was $0.015 \mu \mathrm{g} / \mathrm{cm}^{2}$, and the coefficient of variation was $30.43 \%$. The distribution uniformity of droplet deposition is obviously better than the other two treatments, and the prevention and control of diseases and insect pests in the wheat field showed a good control effect. The aphid control effect was $87.92 \%$ on the seventh day after spraying, which was significantly higher than that of the conventional spray treatment $(76.43 \%$ with the electrostatic oil agent and $66.47 \%$ with the conventional water-based agent). Liu [46] designed a high-voltage electrostatic generator with smaller volume and mass based on the optimized structure parameters of the coneshaped electrode and the determined dosage form of the special electrostatic liquid agent for aviation. It was more suitable for plant protection UAVs, aimed at the current problems such as the poor charging effect of droplets, poor applicability of aerial spraying agents, complex high-voltage electrostatic generator system, and heavy high-voltage electrostatic generator. In addition, a set of electrostatic spray systems that can be applied to six-rotor and single-rotor plant protection UAVs was developed, as shown in Figure 5. The system was mounted on the plant protection UAV and carried out the experiment in the cotton and rice-growing areas of Changji, Xinjing, Shihezi, Xinjing, and Ledong, Hainan. The results of 
spraying operation of hybrid breeding rice growth regulator and defoliating cotton agent by plant protection UAV showed that when spraying rice growth regulator by plant protection UAV, the effect of electrostatic spraying could be up to $20 \%$ higher than that of non-static spraying, and the effects of spraying different chemicals were different. When sprayed the cotton defoliant, the coverage rate of droplet increased by $140 \%$, the defoliation efficacy increased by $12.22 \%$, and the cotton boll opening rate increased by $18.55 \%$.

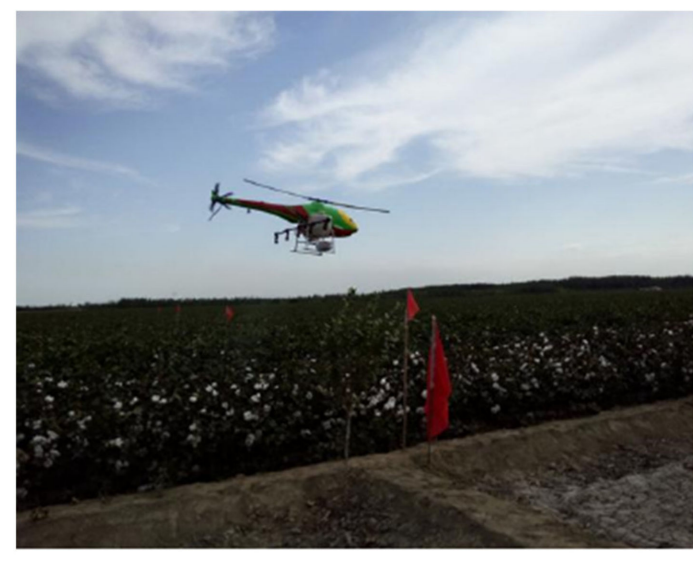

(a)

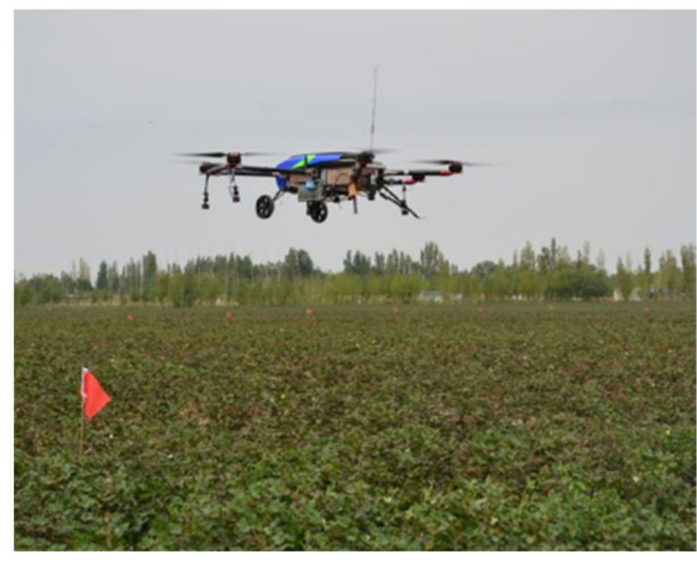

(b)

Figure 5. HY-B-15L single-rotor plant protection unmanned helicopter for cotton defoliant spray (a) and TXA616 plant protection UAV for rice growth regulator spray (b) [46].

\subsection{Summary}

To sum up, a large number of field experiments have been conducted in China to test the actual performance of the electrostatic spray system based on UAVs. For the convenience of comparative analysis, Table 1 summarizes the researches on UAV-based electrostatic spray systems. From the perspective of the test scheme, the system pressure, flight height and speed, charging voltage, rotor wind speed, and their effects on each other were studied. Chinese scholars have also completed a lot of work using theoretical simulations of the spray system, the improvement of the electrostatic nozzle, and the optimization of the aerial chemicals. In terms of the mode of charge, most studies adopt the induction mode of charge with the highest safety. The inductive charging voltage is usually between $2 \mathrm{kV}$ and $15 \mathrm{kV}$, and the electrode making and insulation methods are easy to be realized, which is the most developed method of charging droplets at present [47]. In addition, contact charging has also been tried in China, which has also achieved good results $[34-36,41,45]$. However, it needs to keep the absolute insulation of the spray system in the charging process, which puts forward high requirements for the design method and safety.

Figure 6 illustrates the key achievements of the aerial electrostatic spray technology and the research groups over a timeline. Since 2015, China's UAV-based aerial electrostatic spray technology has developed rapidly. In general, although the UAV-based electrostatic spray technology is a new technology, it is gradually being improved. Compared with the electrostatic spray system on manned aircraft, plant protection UAVs have more development prospects in China at present. With the operation area covered exceeding 67 million $\mathrm{hm}^{2}$, the plant protection UAV has developed from an early experimental product into a common agricultural production machine in China [48]. It is of great practical significance to study the fusion and influence mechanism of UAV and aerial electrostatic spray systems, which contributes to the field of agricultural aviation plant protection in the future. 
Table 1. Study on UAV-based Electrostatic Spray System.

\begin{tabular}{|c|c|c|c|c|c|c|}
\hline Test Device & Charged Mode & Test Target & Test Method & Evaluating Indicator & Test Environment & Researchers and Affiliation \\
\hline XY8D UAV & Induction & Rice & Different flight height & $\begin{array}{l}\text { Droplet deposition } \\
\text { characteristics }\end{array}$ & Field test & $\begin{array}{l}\text { Ru, et al., Nanjing Forestry } \\
\text { University }\end{array}$ \\
\hline $\begin{array}{l}\text { AF-811 unmanned } \\
\text { helicopter }\end{array}$ & Induction & Copy paper & $\begin{array}{l}\text { Comparison of } \\
\text { electrostatic spray and } \\
\text { non-electrostatic spray }\end{array}$ & $\begin{array}{c}\text { Effective spray } \\
\text { amplitude and droplet } \\
\text { deposition } \\
\text { characteristics }\end{array}$ & Outdoor & $\begin{array}{l}\text { Jin, et al., Nanjing Forestry } \\
\text { University }\end{array}$ \\
\hline $\begin{array}{l}\text { YG20-6 type } \\
\text { six-rotor UAV }\end{array}$ & Induction & Water sensitive paper & $\begin{array}{l}\text { Comparison of } \\
\text { electrostatic spray and } \\
\text { non-electrostatic spray }\end{array}$ & $\begin{array}{c}\text { Measurement of effective } \\
\text { spray amplitude, droplet } \\
\text { penetration, and droplet } \\
\text { deposition }\end{array}$ & Outdoor & $\begin{array}{l}\text { Lian, Heilongjiang Bayi } \\
\text { Agricultural University }\end{array}$ \\
\hline $\begin{array}{l}\text { F-50 plant-based } \\
\text { unmanned helicopter }\end{array}$ & Contact & Sample tape, rice & $\begin{array}{c}\text { Comparison of different } \\
\text { charge modes } \\
\text { (non-electrostatic, } \\
\text { induction electrostatic, } \\
\text { contact electrostatic) }\end{array}$ & $\begin{array}{c}\text { Droplet deposition } \\
\text { measurement and } \\
\text { coefficient of variation of } \\
\text { deposition amount }\end{array}$ & Field test & Cai, Jiangsu University \\
\hline $\begin{array}{l}\text { HY-B-15L single rotor } \\
\text { plant protection } \\
\text { unmanned helicopter, } \\
\text { TXA micro } \\
\text { six-rotor UAV }\end{array}$ & Induction & $\begin{array}{l}\text { Crossbreeding rice, } \\
\text { Cotton picked by } \\
\text { machine }\end{array}$ & $\begin{array}{l}\text { Comparison of different } \\
\text { water agents, number of } \\
\text { rotors, and crops }\end{array}$ & $\begin{array}{l}\text { Droplet deposition } \\
\text { characteristics and } \\
\text { pharmacodynamics }\end{array}$ & Field test & $\begin{array}{c}\text { Liu, South China Agricultural } \\
\text { University }\end{array}$ \\
\hline $\begin{array}{l}\text { Integrated spray } \\
\text { test stand }\end{array}$ & Induction & Water sensitive paper & $\begin{array}{l}\text { Comparison of } \\
\text { electrostatic spray and } \\
\text { non-electrostatic spray }\end{array}$ & $\begin{array}{l}\text { Density of droplet } \\
\text { deposition }\end{array}$ & Indoor & $\begin{array}{l}\text { Zhang et al., Heilongjiang } \\
\text { Bayi Agricultural University }\end{array}$ \\
\hline $\begin{array}{l}\text { 3WQF120-12 } \\
\text { oil-operated single-rotor } \\
\text { plant protection UAV }\end{array}$ & Contact & wheat & $\begin{array}{l}\text { Comparison between } \\
\text { electrostatic oil agent } \\
\text { and conventional } \\
\text { water-based agent, } \\
\text { electrostatic spray and } \\
\text { conventional } \\
\text { spray system }\end{array}$ & $\begin{array}{l}\text { Distribution uniformity } \\
\text { of droplet deposition } \\
\text { and its control effect on } \\
\text { wheat aphid and rust }\end{array}$ & Field test & $\begin{array}{c}\text { Wang et al., China Agriculture } \\
\text { University }\end{array}$ \\
\hline $\begin{array}{l}\text { FR-200 type large-load } \\
\text { unmanned helicopter }\end{array}$ & Induction & Water sensitive paper & $\begin{array}{l}\text { Charged voltage, flight } \\
\text { speed, flight height, and } \\
\text { crosswind wind speed }\end{array}$ & $\begin{array}{c}\text { Droplet deposition } \\
\text { characteristics and } \\
\text { droplet drift rate }\end{array}$ & Field test & $\mathrm{Bu}$, Jiangsu University \\
\hline
\end{tabular}


Table 1. Cont.

\begin{tabular}{|c|c|c|c|c|c|c|}
\hline Test Device & Charged Mode & Test Target & Test Method & Evaluating Indicator & Test Environment & Researchers and Affiliation \\
\hline $\begin{array}{l}\text { response surface } \\
\text { methodology (RSM) }\end{array}$ & Induction & - & $\begin{array}{l}\text { Nozzle diameter, nozzle } \\
\text { pressure, and } \\
\text { electrostatic voltage }\end{array}$ & $\begin{array}{l}\text { Droplet deposition } \\
\text { characteristics and } \\
\text { charge to mass ratio }\end{array}$ & Simulation & Wu et al., Guizhou University \\
\hline $\begin{array}{l}\text { W730S four-rotor } \\
\text { semi-automatic plant } \\
\text { protection UAV }\end{array}$ & Induction & Effusion cylinder & - & $\begin{array}{l}\text { Droplet deposition } \\
\text { measurement and spray } \\
\text { flow stability }\end{array}$ & Indoor & $\begin{array}{c}\text { Wang et al., Hangzhou Dianzi } \\
\text { University }\end{array}$ \\
\hline $\begin{array}{l}\text { An indoor spray bar } \\
\text { electrostatic spray } \\
\text { system test platform }\end{array}$ & Induction & Water sensitive paper & $\begin{array}{l}\text { Nozzle diameter, nozzle } \\
\text { pressure, and } \\
\text { spraying height }\end{array}$ & $\begin{array}{l}\text { Droplet deposition } \\
\text { characteristics }\end{array}$ & Indoor & Lu et al., Guizhou University \\
\hline $\begin{array}{l}\text { Aerial electrostatic } \\
\text { spraying system } \\
\text { suspension test bench }\end{array}$ & Contact & Art Paper & $\begin{array}{l}\text { Spraying height, } \\
\text { spray time, } \\
\text { and charging voltage }\end{array}$ & $\begin{array}{l}\text { Droplet deposition } \\
\text { characteristics and } \\
\text { back-front ratio }\end{array}$ & Indoor & $\begin{array}{l}\text { Zhao et al., Shandong } \\
\text { University of Technology }\end{array}$ \\
\hline $\begin{array}{l}\text { Charge aerosol spray } \\
\text { test bench }\end{array}$ & Induction & White plastic board & $\begin{array}{c}\text { Charging voltage, spray } \\
\text { pressure, electrode ring } \\
\text { diameter, } \\
\text { and electrode spacing }\end{array}$ & $\begin{array}{l}\text { Spray charge-to-mass } \\
\text { ratio and droplet size }\end{array}$ & Indoor & Wang et al., Jiangsu University \\
\hline Fixed spray simulator & Induction & Dracaena & $\begin{array}{c}\text { Electrode material, } \\
\text { charging voltage, } \\
\text { spray pressure, and } \\
\text { nozzle diameter }\end{array}$ & Droplet deposition & Indoor & $\begin{array}{l}\text { Lan et al., South China } \\
\text { Agricultural University }\end{array}$ \\
\hline Neuroshell & Induction & - & $\begin{array}{l}\text { Temperature, humidity, } \\
\text { electrode ring diameter, } \\
\text { charging voltage, and } \\
\text { nozzle flow }\end{array}$ & $\begin{array}{l}\text { Spray charge-to- } \\
\text { mass ratio }\end{array}$ & Simulation & $\begin{array}{l}\text { Li et al., Heilongjiang Bayi } \\
\text { Agricultural University }\end{array}$ \\
\hline
\end{tabular}




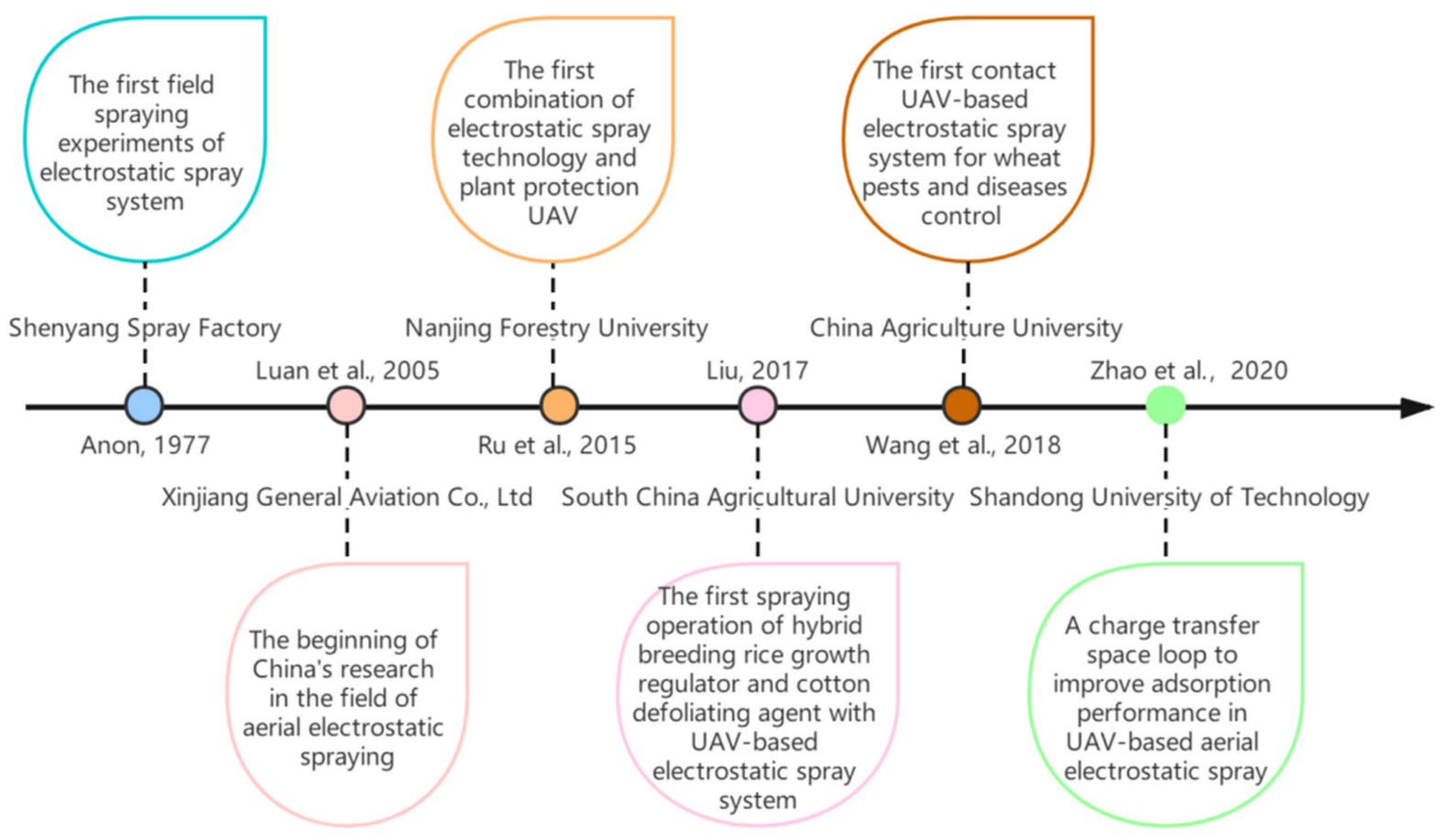

Figure 6. Key milestones and research groups working on aerial electrostatic spray technology.

\section{Analysis and Prospects}

The exploration of UAV-based electrostatic spray technology expands a new research perspective for the research of agricultural aviation electrostatic spray technology. The continuous improvement of the technology brings new opportunities for the application of aerial electrostatic spray systems on commercial plant protection UAVs in China. However, according to the current research progress, still, the following key technical elements need further exploration.

\subsection{Measurement Technology of Charged Droplets}

Droplet charge to mass ratio is a term associated with aerial electrostatic spray technology, and the measurement results of charge to mass ratio provide a reference for the evaluation of electrostatic spray system performance. In the absence of interference (e.g., indoors), the droplet charge to mass ratio is positively correlated with the deposition effect [49]. However, when working in an outdoor environment, there is usually a big difference between the droplet charge to mass ratios at the nozzle end and the terminal target, which requires the terminal measuring device to evaluate the charge amount. However, due to the absence of electrical grounding, the device that collects charged droplets often results in an inconsistent result with the actual effect of settling on the target [50]. For the electrostatic spray technology, the electric field intensity varies with the plant form, liquid conductivity, and environmental factors. For example, the electric field near the tip or terminal part of the leaf is the strongest [51]. Law [52] reported that gaseous discharges between sharp leaf tips and incoming charged spray clouds had been shown to limit deposition.

In many studies, aerial electrostatic spray had a better deposition effect compared with conventional electrostatic spray and non-electrostatic spray, but there are not a few reports that the effect of electrostatic spray is not satisfactory $[1,49,53]$. However, it remains to be further confirmed whether the difference in operation effect is caused by a sharp reduction in the charge to mass ratio of charge droplets, faulty experimental design scheme, or environmental influence. In recent years, more detection methods such as laser particle size analyzer have been continuously applied to the measurement of droplets effect in 
China $[54,55]$. However, there are many problems such as high manufacturing cost, large measurement error, and complex measurement process. Therefore, it is necessary to develop a droplet characteristic detection technology suitable for aerial electrostatic spray systems to monitor the real state of charged droplets.

\subsection{Impact of $U A V$ Rotor Wind Field on Charged Droplets}

The wind field on a manned fixed-wing aircraft causes charged droplets to settle in the direction of flight towards the area over which the aircraft passes. However, the wind field of a multi-rotor plant protection $\mathrm{UAV}$ is chaotic and changeable. It is not a regular wind field in a single direction. Moreover, due to the dual interference of ambient wind and rotor wind field, the charged droplet deposition process is more complicated in the actual operation scenario. Existing studies have basically ignored the working state of bipolar electrostatic spray system under the action of multiple rotor wind fields, the attracting process of positive and negative charged droplets, and the influence of droplets on the humidity of inductive charging electrodes. However, the impact is huge in that the characteristic of charged droplet property undoubtedly loses if the attraction of the charged droplets with positive and negative polarity is affected. In addition, wet electrodes will also make the electrically charged performance worse. Therefore, the influence of UAV rotor wind fields on charged droplets should be paid more attention in future research.

PIV (Particle Image Velocimetry) and other techniques can be used to simulate the droplet settling state under the influence of the rotor wind field, natural environmental wind, multiple gradient crosswinds, and other factors, so as to establish a theoretical system for reducing the influence of the rotor UAV downwash wind field and even utilizing the wind field action.

\subsection{Comparative Study of Various Charging Methods}

The induction charging mode was determined from the early stage of aerial electrostatic spray technology research in the United States, and it has been adopted in commercial electrostatic spray systems. Induction charging has the advantages of low charging voltage and low application threshold. It is a safe and effective method for charging droplets. Most Chinese scholars have also applied the induction charging method in their research. However, in addition to induction, there are also contact and corona ways to charge droplets. Corona charging voltage is very high, up to $30 \mathrm{kV}$. It can be used for conductive and non-conductive liquids with low insulation requirements. The contact charging voltage is required to be between corona type and induction type, but the insulation requirements are higher. Although the corona type with high charging voltage and the contact type with high insulation requirements still need a lot of basic research to clarify the charging mechanism and eliminate application risks, the disadvantages of the induction charging mode with poor charging effect cannot be ignored. Previous studies have shown that the contact charging method is able to generate a larger target current when compared with the induction charging method [47]. In recent years, there have been reports on contact charging methods in the research of UAV-based electrostatic spray technology with gratifying test results. In the future, it is necessary to carry out comparative studies of various charging methods in order to evaluate the operation effect of aerial electrostatic spray technology under different charging methods.

\subsection{Accumulation of Aerial Electrostatic Spray Technology Research Based on Agricultural UAVs}

During the early stage of China's agricultural aviation electrostatic spray technology research, the design and test were carried out on manned fixed-wing aircraft and helicopter platforms. In recent years, plant protection UAVs have provided Chinese growers with a lower barrier to entry and a higher level of applicability. Chinese scholars have carried on beneficial exploration for UAV-based electrostatic spray technology according to different UAV models, field crops, operating parameters, and electrostatic nozzle parameters, but the main research emphasis is still on the contrast test of electrostatic spray and 
non-electrostatic spray to verify the operation effect of charged droplets. The research accumulation of airborne electrostatic spray technology based on agricultural UAV platforms is still less. It is not mature at the application level because the morphological characteristics of various crops and the farmland environment need more experimental data support. For example, (1) Relevant studies on the system construction, composition, and weight control of the electrostatic spray system lack continuity; (2) whether the operation with aerial electrostatic spray system is affected by surrounding facilities such as high-voltage lines, or whether it is incompatible with the flight control system of high-precision and fully autonomous plant protection UAV, is still unknown; (3) at present, the practical application of aerial electrostatic spray system in the field is limited to spraying water and water-based pesticides, and there is a lack of in-depth discussion on the research of the special electrostatic liquid pesticides and the electrical conductivity of pesticides for aerial spraying application; (4) working parameters of the spray system, such as charging voltage, system pressure and spraying speed, selection of flight speed and altitude, characteristics of aviation agents, and environmental factors such as temperature, humidity, and wind speed, all affect the settling process of charged droplets. Therefore, it is necessary to observe the droplet characteristics by studying their interaction effects; (5) the development trend of most commercial agricultural UAVs in China is integrating pesticide spraying, seed sowing, and fertilizer spreading together with fully autonomous and high-precision operation. Therefore, it is necessary to consider whether the integration of aerial electrostatic spray system, UAV working systems, and flight control system will cause mutual interference.

\section{Conclusions}

The development of aerial electrostatic spray technology in China, especially UAVbased aerial electrostatic spray technology, was analyzed in this review from nozzle modification, technical feasibility tests, mechanisms influencing each factor, and field spray efficiency tests. According to the literature retrieved, the research of China's aerial electrostatic spray technology in the past five years has focused on the innovative exploration of UAVs as a platform. Combined with the current development of agricultural plant protection and industrial application practice, UAV-based aerial electrostatic spray technology has wider developmental potential in China. In the future, the development plans should be made around the basic research, field test, commercialization, demonstration, and service guidance. In addition, researchers are recommended to pay attention to the integrated design of UAV and aerial electrostatic spray systems and to formulate the application standard of aerial electrostatic spray technology in China.

Author Contributions: Conceptualization, Y.Z., Y.L., and X.H.; methodology, X.H., Y.Z., and W.Z.; software, X.L. and W.Z.; validation, X.H. and W.Z.; formal analysis, X.H. and L.W.; investigation, Y.Z., X.H., and L.W.; resources, X.H.; data curation, X.H.; writing-original draft preparation, X.H., K.Y., and Y.Z.; writing-review and editing, Y.Z. and K.Y.; visualization, X.L.; supervision, W.Z. and J.D.; project administration, Y.Z., Y.L., and J.D.; funding acquisition, Y.Z. All authors have read and agreed to the published version of the manuscript.

Funding: This research was funded by Key Field Research and Development Plan of Guangdong Province, China, grant number 2019B020221001, Science and Technology Plan Project of Guangdong Province, China, grant number 2018A050506073, Guangdong Modern Agricultural Industry Generic Key Technology Research and Development Innovation Team Project, grant number 2020KJ133, National Key Research and Development Program, grant number 2018YFD0200304, and the 111 Project, grant number D18019.

Institutional Review Board Statement: Not applicable.

Informed Consent Statement: Not applicable.

Data Availability Statement: Not applicable.

Conflicts of Interest: The authors declare no conflict of interest. 


\section{References}

1. Zhang, Y.L.; Lan, Y.B.; Fritz, B.K.; Xue, X.Y. Development of aerial electrostatic spraying systems in the United States and applications in China. Trans. Chin. Soc. Agric. Eng. 2016, 32, 1-7, (In Chinese with English abstract). [CrossRef]

2. Martin, D.E.; Latheef, M.A. Efficacy of electrostatically charged glyphosate on ryegrass. J. Electrost. 2017, 90, 45-53. [CrossRef]

3. Tavares, R.M.; Cunha, J.P.; Alves, T.C.; Bueno, M.R.; Silva, S.M.; Zandonadi, C.H. Electrostatic spraying in the chemical control of Triozoida limbata (Enderlein) (Hemiptera: Triozidae) in guava trees (Psidium guajava L.). Pest Manag. Sci. 2016, 73, 1148-1153. [CrossRef] [PubMed]

4. Martin, D.E.; Latheef, M.A.; López, J.D. Electrostatically charged aerial application improved spinosad deposition on early season cotton. J. Electrost. 2019, 97, 121-125. [CrossRef]

5. Carlton, J.B.; Isler, D.A. Development of a device to charge aerial sprays electrostatically. Agric. Aviat. 1966, 8, 44-51.

6. Carlton, J.B. Technique to Reduce Chemical Usage and Concomitant Drift from Aerial Sprays. United States Department of. Agriculture Patents No. 5975425, 2 November 1999.

7. Spectrum Electrostatic Sprayers, Inc. Available online: http://spectrumsprayer.com/company.html (accessed on 11 May 2020).

8. Inculet, I.I.; Fischer, J.K. Electrostatic aerial spraying. IEEE Trans. Ind. Appl. 1989, 25, 558-562. [CrossRef]

9. Da Cunha, J.P.A.R.; Barizon, R.R.M.; Ferracini, V.L. Assalin, Spray drift and caterpillar and stink bug control from aerial applications with electrostatic charge and atomizer on soybean crop. Eng. Agrícola 2017, 37, 1163-1170. [CrossRef]

10. Martin, D.E.; Latheef, M.A.; Lopez, J.D.; Duke, S.E. Aerial Application Methods for Control of Weed Species in Fallow Farmlands in Texas. Agronomy 2020, 10, 1764. [CrossRef]

11. Anon. Introduce a new technology of pesticide application-electrostatic spray. For. Sci. Technol. 1974, 1, 18.

12. Anon. Preliminary test of pesticide electrostatic spray. For. Sci. Technol. 1978, 2, 16-17.

13. He, X.K.; Yan, K.R.; Chu, J.Y.; Wang, J.; Zeng, A.J.; Liu, Y.J. Design and testing of the automatic target detecting, electrostatic, air assisted, orchard sprayer. Nongye Gongcheng Xuebao Trans. Chin. Soc. Agric. Eng. 2003, 19, 78-80, (In Chinese with English abstract).

14. Yu, Y.C.; Wang, B.H.; Shi, J.Z.; Li, X.F. Design and experimental study of combined-charging hydraulic electrostatic spraying box. Trans. Chin. Soc. Agric. Eng. 2005, 21, 85-88, (In Chinese with English abstract).

15. Zhang, J.; Zheng, J.Q. Experiment on the variations of droplet diameter distribution and local flow rate over radial direction for the electrostatic spray process. Trans. Chin. Soc. Agric. Eng. 2009, 25, 104-109, (In Chinese with English abstract). [CrossRef]

16. Jia, W.D.; Hu, H.C.; Chen, L.; Chen, Z.G.; Wei, X.H. Performance experiment on spray atomization and droplets deposition of wind-curtain electrostatic boom spray. Trans. Chin. Soc. Agric. Eng. 2015, 31, 53-59, (In Chinese with English abstract). [CrossRef]

17. Zhou, L.F.; Zhang, L.; Xue, X.Y.; Qin, W.C.; Sun, Z.; Zhou, Q.Q.; Chen, C. Design and test of double air channel auxiliary electrostatic sprayer. Jiangsu Agric. Sci. 2017, 45, 192-196, (In Chinese with English abstract). [CrossRef]

18. Ma, X.; Guo, L.J.; Wen, Z.C.; Wei, Y.H.; Xiao, R.H.; Zeng, H. Atomization characteristics of multi-nozzle electrostatic spray and field experiment. Trans. Chin. Soc. Agric. Eng. 2020, 36, 73-82, (In Chinese with English abstract). [CrossRef]

19. Dai, Q.F.; Hong, T.S.; Song, S.R.; Li, Z.; Chen, J.Z. Influence of pressure and pore diameter on droplet parameters of hollow cone nozzle in pipeline spray. Trans. Chin. Soc. Agric. Eng. 2016, 32, 97-103, (In Chinese with English abstract). [CrossRef]

20. Luan, H.; Zhang, Q.; Wang, W.X. Installation and modification of Z03K000B electrostatic spray system and flight tests. Xin-jiang Reclam. Technol. 2006, 5, 46-47, (In Chinese with English abstract).

21. Zhang, Y.L.; Huang, X.R.; Wang, L.L.; Deng, J.Z.; Zeng, W.; Lan, Y.B.; Muhammad, N.T. Progress in foreign agricultural aviation electrostatic spray technologies and references for China. Trans. Chin. Soc. Agric. Eng. 2021, 37, 50-59, (In Chinese with English abstract). [CrossRef]

22. Ru, Y.; Zheng, J.Q.; Zhou, H.P.; Shu, C.R. Design and experiment of double nozzle of aerial electrostatic sprayer. Trans. Chin. Soc. Agric. Mach. 2007, 38, 58-61.

23. Zhou, H.P.; Ru, Y.; Shu, C.R.; Jia, Z.C. Improvement and experiment of aerial electrostatic spray device. Trans. Chin. Soc. Agric. Eng. 2012, 28, 7-12, (In Chinese with English abstract). [CrossRef]

24. Ru, Y.; Jin, L.; Zhou, H.P.; Shu, C.R. Effect of high-voltage electrostatic field on droplet charging based on cone-shaped electrode. High Volt. Eng. 2014, 40, 2721-2727, (In Chinese with English abstract). [CrossRef]

25. Jin, L.; Ru, Y.; Sun, M.L.; Jia, Z.C.; Wang, B.X. Performance experiments of aerial electrostatic nozzle with cone shaped electrode. J. Nanjing For. Univ. (Nat. Sci. Ed.) 2015, 39, 155-160, (In Chinese with English abstract). [CrossRef]

26. Yang, Z.; Niu, M.M.; Li, J.; Xu, X.; Sun, Z.Q.; Xue, K.P. Influence of lateral wind and electrostatic voltage on spray drift of electrostatic sprayer. Trans. Chin. Soc. Agric. Eng. 2015, 31, 39-45, (In Chinese with English abstract). [CrossRef]

27. Chen, H.L.; Zhao, Y.C. Electrostatic induction field and charging property of droplet in electrostatic spraying process. High Volt. Eng. 2010, 36, 2519-2524, (In Chinese with English abstract). [CrossRef]

28. Zhang, D.Y.; Lan, Y.B.; Chen, L.P.; Wang, X.; Liang, D. Current status and future trends of agricultural aerial spraying technology in China. Trans. Chin. Soc. Agric. Mach. 2014, 45, 53-59, (In Chinese with English abstract). [CrossRef]

29. Tian, Z.W.; Xue, X.Y.; Li, L.; Cui, L.F.; Wang, G.; Li, Z.J. Research status and prospects of spraying techology of plant-protection unmanned aerial vehicle. J. Chin. Agric. Mech. 2019, 40, 37-45, (In Chinese with English abstract). [CrossRef]

30. Li, J.Y.; Lan, Y.B.; Shi, Y.Y. Research progress on airflow characteristics and field pesticide application system of rotary-wing UAV. Trans. Chin. Soc. Agric. Eng. 2018, 34, 104-118, (In Chinese with English abstract). [CrossRef] 
31. Ru, Y.; Jin, L.; Jia, Z.C.; Bao, R.; Qian, X.D. Design and experiment on electrostatic spraying system for unmanned aerial ve-hicle. Trans. Chin. Soc. Agric. Eng. 2015, 32, 42-47, (In Chinese with English abstract). [CrossRef]

32. Wang, Y.T.; Wu, K.H. Research on an electrostatic spraying system for multi-rotor plant protection UAV. Jiangsu Agric. Sci. 2020, 48, 225-230, (In Chinese with English abstract). [CrossRef]

33. Jin, L.; Ru, Y. Research on UAV-based aerial electrostatic spraying system. J. Agric. Mech. Res. 2016, 38, 227-230, (in Chinese with English abstract). [CrossRef]

34. Lian, Q. Experimental Research on Electrostatic Spray System of Multi-Rotor UAV. Master's Thesis, Heilongjiang Bayi Agricultural University, Daqing, China, 2016.

35. Cai, Y.L. Design and Test of Contact Electrostatic Spray System for Low-Altitude UAV. Master's Thesis, Jiangsu University, Zhenjiang, China, 2017.

36. Zhao, D.N.; Lan, Y.B.; Shen, W.G.; Wang, S.Z.; Abhishek, D. Development of a charge transfer space loop to improve ad-sorption performance in aerial electrostatic spray. Int. J. Agric. Biol. Eng. 2020, 13, 50-55. [CrossRef]

37. Yanliang, Z.; Qi, L.; Wei, Z. Design and test of a six-rotor unmanned aerial vehicle (UAV) electrostatic spraying system for crop protection. Int. J. Agric. Biol. Eng. 2017, 10, 68-76. [CrossRef]

38. Bu, J.Z. Experimental Study on Deposition and Drift Characteristics of Electrostatic Spray for Large-Load Unmanned Helicopter. Master's Thesis, Jiangsu University, Zhenjiang, China, 2019.

39. Wu, Y.; Lu, J.; Wang, Y. Research on Multiresponse Robustness Optimization for Unmanned Aerial Vehicle Electrostatic Spray System. Fundam. Mach. Theory Mech. 2020, 77, 719-728. [CrossRef]

40. Lu, J.J.; Chen, J.D.; Wu, Y.D.; Wang, B. Agricultural aviation research aeronautical electrostatic spray system performance. J. Agric. Mech. Res. 2019, 41, 174-179, (In Chinese with English abstract). [CrossRef]

41. Zhao, D.N.; Lan, Y.B.; Shen, W.G. Building of aerial electrostatic spraying system and exploration on the influencing factors of droplet deposition effect. J. Agric. Mech. Res. 2021, 43, 204-207, (In Chinese with English abstract). [CrossRef]

42. Wang, J.F.; Gu, W.K.; Wang, X.Y.; Chu, J.J. Experimental study on charging performance and spray characteristics of induction charged spray. High Volt. Eng. 2015, 41, 504-509, (In Chinese with English abstract). [CrossRef]

43. Lan, Y.B.; Zhang, H.Y.; Wen, S.; Li, S.H. Analysis and experiment on atomization characteristics and spray deposition of electrostatic nozzle. Trans. Chin. Soc. Agric. Mach. 2018, 49, 130-139, (In Chinese with English abstract). [CrossRef]

44. Li, Y.F.; Hu, J.; Li, Q.D.; Zhao, M.M. Study on influencing factors of airborne electrostatic fog trapping. Trans. Chin. Soc. Agric. Mach. 2019, 41, 171-176, (In Chinese with English abstract). [CrossRef]

45. Wang, S.L.; He, X.K.; Song, J.L.; Zhong, C.S.; Wang, Z.C.; Qi, P.; Ling, Y. Charging and spraying performance test of bipolar contact electrostatic spraying system for unmanned aerial vehicle. Trans. Chin. Soc. Agric. Eng. 2018, 34, 82-89, (In Chinese with English abstract). [CrossRef]

46. Liu, W.L. Design and Experiment of Electrostatic Spraying System for Plant Protection Unmanned Aerial Vehicle. Master's Thesis, South China Agricultural University, Guangzhou, China, 2017.

47. Zhao, S.; Castle, G.P.; Adamiak, K. Comparison of conduction and induction charging in liquid spraying. J. Electrost. 2005, 63, 871-876. [CrossRef]

48. Agropages. China's Crop Protection UAV Development Report 2020. Available online: http://news.agropages.com/News/ NewsDetail---38284.htm (accessed on 17 March 2021).

49. Kirk, I.W.; Hoffmann, W.C.; Carlton, J.B. Aerial electrostatic spray system performance. Trans. ASAE 2001, 44, 1089-1092. [CrossRef]

50. Martin, D.E.; Latheef, M.A. Aerial electrostatic spray deposition and canopy penetration in cotton. J. Electrost. 2017, 90, 38-44. [CrossRef]

51. Dai, Y.; Law, S. Modeling the transient electric field produced by a charged pollen cloud entering a flower. In Proceedings of the IAS '95. Conference Record of the 1995 IEEE Industry Applications Conference Thirtieth IAS Annual Meeting, Orlando, FL, USA, 8-12 October 1995; Institute of Electrical and Electronics Engineers (IEEE): New York, NY, USA, 2002; Volume 2, pp. $1395-1402$.

52. Law, S.E. Electrostatic Pesticide Spraying: Concepts and Practice. IEEE Trans. Ind. Appl. 1983, 2, 160-168. [CrossRef]

53. Martin, D.E.; Lopez, J.D.; Hoffmann, W.C.; Fritz, B.K.; Lan, Y. Field Evaluation of Spinosad Aerial Applications for Thrips Control on Cotton1. Southwest. Ėntomol. 2007, 32, 221-228. [CrossRef]

54. Zhang, R.R.; Chen, L.P.; Lan, Y.B.; Xu, G.; Kan, J.; Zhang, D.Y. Development of a deposit sensing system for aerial spraying application. Trans. Chin. Soc. Agric. Mach. 2014, 45, 123-127, (In Chinese with English abstract). [CrossRef]

55. He, Y.; Wu, J.J.; Fang, H.; Zheng, Q.S.; Xiao, S.P.; Cen, H.Y. Research on deposition effect of droplets based on plant protection unmanned aerial vehicle: A review. J. Zhejiang Univ. (Agric. Life Sci.) 2018, 44, 392-398, (In Chinese with English abstract). [CrossRef] 